\title{
Perinatal outcomes following Helping Babies Breathe training and regular peer-peer skills practice among village midwives in Sudan
}

\author{
AME Arabi, ${ }^{1}$ SA Ibrahim, ${ }^{1}$ M Abdel-Rahman, ${ }^{2,3}$ MS Abdalla, ${ }^{1}$ SE Ahmed, ${ }^{4}$ EP Dempsey, ${ }^{4}$ \\ CA Ryan ${ }^{4}$
}

'Department of Paediatrics and Child Health, Faculty of Medicine, University of Khartoum, Khartoum, Sudan ${ }^{2}$ Department of Statistics, Faculty of Mathematical Sciences, University of Khartoum, Khartoum, Sudan ${ }^{3}$ Department of Public Health, College of Health Sciences, Qatar University, Doha, Qatar ${ }^{4}$ Department of Paediatrics and Child Health, Cork University Maternity Hospital, Cork, Ireland

Correspondence to Dr AME Arabi, Department of Paediatrics and Child Health Faculty of Medicine, University of Khartoum, PO Box 102 Khartoum, Sudan; draliarabi99@gmail.com

Received 1 February 2017 Revised 7 June 2017 Accepted 12 June 2017

\section{(D) crossark}

To cite: Arabi AME, Ibrahim SA, AbdelRahman M, et al.

Arch Dis Child Published Online First: [please include Day Month Year].

doi:10.1136/

archdischild-2017-312809

\section{ABSTRACT}

Background Over $80 \%$ of deliveries in Sudan occur in rural areas, attended by village midwives (VMWs). Objective To determine the impact of Helping Babies Breathe training and regular peer-peer skills practice (HBBT ${ }^{+R P P S P}$ ) on VMW resuscitation practices and outcomes.

Methods In a prospective community-based intervention study, 71/82 VMWs, reporting to six East Nile rural medical centres, with previous experience in community health research, consented to $\mathrm{HBBT}^{+\mathrm{RPPSP}}$. Outcomes included changes in the resuscitation practices, fresh stillbirths (FSB) and early neonatal deaths $<1$ week (ENND).

Results There were 1350 and 3040 deliveries before and after $\mathrm{HBBT}^{+\mathrm{RPPSP}}$, respectively, with no significant differences between the two cohorts regarding maternal age, education or area of birth. Drying of the newborn increased almost tenfold $(8.4 \%, \mathrm{n}=113$ to $74.9 \%$, $n=1011$ ) while suctioning of the mouth/nose decreased fivefold $(80.3 \%, n=2442$ to $14.4 \%, n=437)$ following $\mathrm{HBBT}^{+\mathrm{RPSPP}}$. Pre-HBBT ${ }^{+\mathrm{RPPSP}} \mathrm{g} / 18$ (50\%) newborns who had mouth-to-mouth ventilation died, compared with 13/119 (11\%) who received bag-mask ventilation post-HBBT ${ }^{\text {RPPSP }}$. Excluding 11 macerated fetuses, there were 55 perinatal deaths: 14 FSB/18 ENND (6 months pre-HBBT ${ }^{\text {RPPSP }}$ ) and $10 \mathrm{FSB} / 13$ ENND (18 months post-HBBT ${ }^{+ \text {RPPSP }}$ ). FSB rates decreased from 10.5 to 3.3 per 1000 births $\left(\left(\chi^{2}\right)=8.6209, p=0.003\right)$, while ENND rates decreased from 13.5 to 4.3 per 1000 live births $\left(\left(\chi^{2}\right)=10.9369, p=0.001\right)$ pre-HBBT ${ }^{+ \text {RPPSP }}$ and post$\mathrm{HBBT}^{+\mathrm{RPPSP}}$, respectively.

Conclusion In a selected group of VMWs, HBBT ${ }^{+R P P S P}$ was associated with improvements in newborn resuscitation and perinatal outcomes. HBBT ${ }^{+R P S P}$ could have immense benefits if propagated nationally to all 17 000 VMWs in Sudan.

\section{INTRODUCTION}

The Sudanese village midwife (VMW) is selected by her community to undergo 2 years of training, after which she is registered and licensed to practise under the supervision of a rural health visitor (RHV). Generally the only health providers in their remote communities, their duties include antenatal care, referral of high-risk pregnancies, home deliveries, postnatal care, registration of births and limited drug dispensation. In Sudan, the proportion of women delivered at home by VMWs remained unchanged at $80 \%$ between 2006 and 2010, ${ }^{12} 3$
What is already known on this topic?

- Over $80 \%$ of Sudanese deliveries occur in isolated villages, attended by a village midwife (VMW).

- Helping Babies Breathe training (HBBT) has been shown to decrease perinatal mortality.

\section{What this study adds?}

- Drying the newborn increased tenfold, while suctioning of the oropharynx decreased fivefold, indicating transfer of HBB skills into VMW practice.

- Bag-mask ventilation was performed by more than half of the VMWs in 3.9\% of deliveries following $\mathrm{HBBT}^{+\mathrm{RPPSP}}$.

- In the pre-HBBT ${ }^{\text {RPPSP }}$ cohort, $9 / 18(50 \%)$ newborns who had mouth-to-mouth ventilation died, compared with 13/119 (11\%) newborns who received bag-mask ventilation post-HBBT ${ }^{+R P P S P}$

while a 2010 national survey showed that firstmonth neonatal mortality remained static at 1990 s levels of 41 per 1000 live births. ${ }^{4}$

The Helping Babies Breathe initiative (HBB) is a global, evidence-based, neonatal resuscitation programme developed by the American Academy of Pediatrics (AAP) and partners, with the aim of producing sustainable improvements in newborn care in resource-limited countries. ${ }^{5}{ }^{6}$ By training health providers on the essential steps of drying, warming, stimulation to breathe, as well as bag-mask ventilation (BMV), up to $30 \%$ of fullterm neonatal deaths and 5\%-10\% of preterm deaths were prevented. ${ }^{7}$ Subsequent trials of HBBT, which also included booster training, have shown even more impressive outcomes. ${ }^{8-13}$ In Tanzania, Msemo et $a l^{8}$ showed a $47 \%$ reduction in 24 -hour early neonatal deaths (ENND) and 24\% reduction in fresh stillbirths (FSB) following continued refresher HBB training (HBBT), while Goudar and colleagues showed a $46 \%$ reduction in FSB in India. ${ }^{90}$ In Nepal, Kc et al ${ }^{11}$ observed a reduction in FSB and 24-hour ENND through repeated quality improvements cycles of HBBT, while Mduma et $a l^{12}$ showed that frequent brief on-site HBBT was 


\section{Original article}

associated with a reduction in 24-hour ENND in a rural hospital in Tanzania. Incorporating early newborn care education into newborn resuscitation training was associated with reductions in 24-hour ENND in Zambia. ${ }^{13}$ While retention of HBB skills remains an ongoing concern, ${ }^{14}$ we calculated that healthcare providers, trained in newborn resuscitation, need to attend 227 deliveries to prevent one neonatal death. ${ }^{15}$

In a previous study, we showed that a selection of Sudanese VMWs acquired and retained resuscitation skills for up to a year following HBBT plus regular peer-peer skills practice $\left(\mathrm{HBBT}^{+\mathrm{RPPSP}}\right){ }^{16}$ The purpose of this paper was to present findings related to newborn resuscitation practices, FSB and firstweek ENND in the same cohort of VMWs before and after $\mathrm{HBBT}^{+\mathrm{RPPSP}}$.

\section{METHODS}

This was a prospective pre-post intervention, community-based, cohort study designed to evaluate the impact of $\mathrm{HBBT}^{+\mathrm{RPPSP}}$ on a selected group of Sudanese VMWs, 6 months prior to and 18 months post-HBBT ${ }^{+ \text {RPPSP }}$. The primary outcomes of interest were FSB and ENND rates. The secondary outcome of interest was changes in the VMWs' newborn resuscitation practices.

\section{Study area and study population}

The sampled area was the East Nile locality, Khartoum Province, with a population of approximately one million people, residing in 307 villages, in an area of 300 square kilometres and approximately 30000 home deliveries each year. Six rural medical centres were selected as study sites because of their previous participation in community health research projects conducted by the Department of Paediatrics and Child Health, University of Khartoum. ${ }^{17}$

\section{HBB training}

None of the study VMWs had previously undertaken HBBT. Following 6 months of baseline perinatal mortality monitoring of the participating VMWs (January through June 2013), a certified master $\mathrm{HBB}$ trainer and three regional $\mathrm{HBB}$ trainers instructed the study VMWs in HBB (July and August 2013). These HBB trainers had themselves been taught in an AAP-approved HBB course in Khartoum, jointly organised by the Sudan Ministry of Health, Cork University Maternity Hospital, Ireland, and master trainers from the AAP. A standard HBB training kit, which included the NeoNatalie manikin simulator, bag and mask, suction bulb syringe, umbilical cord ties, scissors and towels, was used. ${ }^{18}$ All HBB teaching aids were pictorial in nature and did not require reading skills as $60 \%$ of the study VMWs were functionally illiterate. ${ }^{16}$ The HBBT instruction was conducted in Arabic and materials included AAP-approved Arabic translations of the Learner's Workbooks, HBB flip chart, instructor guideline manuals and posters. ${ }^{19}$ Following HBBT, the VMWs were each equipped with a reusable bag-mask device and a suction bulb. Resuscitation practices and perinatal outcomes were then monitored post-HBBT ${ }^{+ \text {RPPSP }}$ for a further 18 months' period (September 2013-February 2015).

\section{Peer-peer resuscitation skills practice}

The participating VMWs reported weekly to one of the six study medical centres. During these weekly visits, they were encouraged to practise on their $\mathrm{HBB}$ resuscitation skills with their peers, using NeoNatalie manikins.

\section{Data collection}

The research team, composed of a medical field inspector Ali ME Arabi (AMEA), two medical field supervisors and six RHVs, met with the study VMWs every week at the each of the six medical centres. Because of their high illiteracy rate, ${ }^{16}$ the VMWs were interviewed by the field researchers initially to record their demographic profiles, and weekly thereafter to document births, the resuscitation practices they had used and the outcome. Data were collected on a paper-based form and later entered into an Excel spreadsheet.

\section{Statistics}

Data were analysed using Stata Statistical Software V.14 ${ }^{20}$ and presented in percentages, means and SD. Pearson $\chi^{2}$ tests were used to test associations between variables, and a two-sided $\mathrm{p}$ value $<0.05$ was considered statistically significant. Ethical approval was provided by the Research Ethics Committee of the Faculty of Medicine, University of Khartoum, the Federal Ministry of Health, Khartoum, and the Cork University Hospitals Research Ethics Committee, Cork, Ireland.

\section{RESULTS}

All 82 VMWs in the six medical centres were approached and 71 consented to and completed the study. Their midwifery experience ranged from 3 to 55 years, with the majority $(62 / 71 ; 87 \%)$ having between 11 and 55 years of experience. Two-thirds $(n=45 / 71,63 \%)$ had attended a professional development course more than 3 years prior to this study. During this study, the majority of VMWs $(n=67 / 71,94 \%)$ attended four data collection/RPPSP sessions per month.

The VMWs conducted a total of 4350 home deliveries during the study period (table 1). There were 1350 (mean 19 deliveries per VMW) during the 6 months pre-HBBT ${ }^{+ \text {RPPSP }}$ and 3040 (mean 43 deliveries per VMW) in the 18 months post-HBBT+RPPSP. There were no differences between the pre-HBBT ${ }^{+ \text {RPPSP }}$ and post-HBBT $^{+ \text {RPPSP }}$ mothers in terms of maternal age at delivery (range 13-50 years), years of maternal education, presentation at birth, infant gender or area of birth (table 1).

According to the VMWs' reports, drying of the newborn increased almost tenfold (8.4\%-74.9\%), while suctioning of the newborn's mouth/nose decreased significantly $(80.3 \%$ $14.4 \%$ ) following HBBT $^{+ \text {RPPSP }}$ (table 2). Prior to HBBT $^{+ \text {RPPSP }}$

\begin{tabular}{|c|c|c|}
\hline & $\begin{array}{l}\text { Pre-HBBT }{ }^{+ \text {RPPSP }} \\
6 \text { months } \\
n(\%)\end{array}$ & $\begin{array}{l}\text { Post-HBBT } \\
18 \text { mopSP } \\
n(\%)\end{array}$ \\
\hline Maternal age (years) & 26.7 & 26.7 \\
\hline Maternal education (years) & 6.9 (SD 4.4) & 6.6 (SD 4.1) \\
\hline Cephalic delivery & $96.9 \%$ & $98.8 \%$ \\
\hline Male/female infants & $52 / 48 \%$ & $51.6 / 48.4 \%$ \\
\hline Births in Omdwanban & $344(25.5 \%)$ & $940(30.9 \%)$ \\
\hline Births in Abugroon & $219(16.2 \%)$ & 440 (14.5\%) \\
\hline Births in Mahas & $259(19.2 \%)$ & $529(17.4 \%)$ \\
\hline Births in Isilat & $166(12.3 \%)$ & $266(8.8 \%)$ \\
\hline Births in Tukunnab & $223(16.5 \%)$ & $645(21.2 \%)$ \\
\hline Births in Ed Babiker & $139(10.3 \%)$ & $220(7.2 \%)$ \\
\hline Total births & 1350 (100\%) & 3040 (100\%) \\
\hline
\end{tabular}

HBBT, Helping Babies Breathe training; RPPSP, regular peer-peer skills practice. 
Table 2 Significant differences in newborn resuscitation practices, fresh stillbirths and early neonatal deaths before and after HBBT ${ }^{+R P S P P}$

\begin{tabular}{lllll}
\hline & Pre-HBBT & \multicolumn{3}{l}{ Post-HBBT $^{+ \text {RPPSP }}$} \\
\hline & $\mathbf{n}$ & $\%$ & $\mathbf{n}$ & $\%$ \\
\hline Drying the newborn & 113 & 8.4 & 2442 & 80.3 \\
\hline Stimulation to breathe & 175 & 13 & 58 & 1.9 \\
\hline Suctioning oropharynx & 1011 & 74.9 & 437 & 14.7 \\
\hline Mouth-to-mouth ventilation & $18 \dagger$ & 1.3 & 0 & 0 \\
Bag-mask ventilation & 0 & 0 & $119 \ddagger$ & 3.9 \\
Fresh stillbirths $\S$ & 14 & 1 & 10 & 0.3 \\
Early neonatal deaths & 18 & 1.3 & 13 & 0.4 \\
\hline Total births & 1305 & 100 & 3040 & 100 \\
\hline
\end{tabular}

$p=0.003 *$ all other parameters $p<0.001)$.

t9 deaths $(50 \%)$.

$\ddagger 13$ deaths (11\%).

$\S 11$ macerated stillbirths excluded (four pre-HBBT ${ }^{+ \text {RPPSP }}$ and seven post-HBBT ${ }^{+ \text {RPPSP}}$ ).

HBBT, Helping Babies Breathe training; RPPSP, regular peer-peer skills practice.

18 VMWs reported mouth-to-mouth ventilation (MMV) on 18 non-breathing newborns (1.3\%), but none following $\mathrm{HBBT}^{+\mathrm{RPPSP}^{2}}$. Over half of the VMWs $(47 / 82,57 \%)$ used BMV on 119 newborns (3.9\%) post-HBBT ${ }^{+ \text {RPPSP }}$. Half of newborns who had MMV died, while only $11 \%$ who received BMV postHBBT $^{+ \text {RPPSP }}$ died.

There were 66 deaths during the 24-month study period: 24 FSB, 31 ENND and 11 macerated fetuses (table 2). FSB rates decreased from 10.5 to 3.3 per 1000 birth $\left(\left(\chi^{1}\right)=8.6209, \mathrm{p}=0.003\right)$, while ENND rates decreased from 13.5 to 4.3 per 1000 live births $\left(\left(\chi^{1}\right)=10.9369, \mathrm{p}=0.001\right)$,

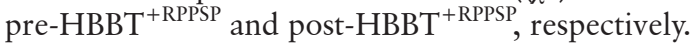

\section{DISCUSSION}

This is the first community-based study on the perinatal impact of the $\mathrm{HBBT}^{+\mathrm{RPPSP}}$ on VMWs in Sudan. It expands on our previous findings that the same VMWs retained their HBB skills up to a year following HBBT $^{+ \text {RPPSP } 16}$ while now revealing transfer of these skills from scenario simulation to actual clinical practice.

We showed that drying the newborn increased tenfold, potentially reducing the perils of neonatal hypothermia, ${ }^{21}$ a persisting problem in sub-Saharan Africa. ${ }^{22}$ Vigorous drying of the newborn may have accounted for the observed reduction in the need to 'stimulate to breathe' following HBBT ${ }^{+ \text {RPPSP }}$. Oral/ nasal suctioning decreased fivefold, lessening the potential for suction-induced apnoea/bradycardia ${ }^{23}$. We also showed that over half of the VMWs used BMV in almost $4 \%$ of deliveries, while MMV (a potentially harmful practice for both the neonate and VMW) was eradicated when the VMW was equipped with a bag-mask device after HBBT. Survival following BMV (50\%) was greater than survival following MMV (11\%), in line with previous reports. ${ }^{24}$ Finally, we observed significant reductions in both FSB and ENND following HBBT ${ }^{+ \text {RPPSP }}$. Other studies have shown similar reductions in FSB rates, ${ }^{8-13}$ occasionally associated with a rise in 24-hour ENND, and have attributed these findings to the fact that HBBT may rectify previously miscategorised 'stillbirths' as correctly categorised ENND. ${ }^{13}$

These findings are important considerations for policy makers planning to upscale HBBT within Sudan or other similar settings. However, it is important to note that this intervention was not just HBBT alone, but included ongoing regular skills practice with peers. The importance of this should not be underestimated as many studies have shown that booster training is vital in maintaining resuscitation skills over time. ${ }^{14}$ In a systematic review, Reisman et $a l^{25}$ showed significantly improved retention of neonatal resuscitation knowledge and skills in health workers who, among other things, practised bag-and-mask skills regularly.

There are a number of potential limitations that should be noted, including that this was a relatively small study in a geographically and socially challenging area. Nevertheless, although resource-poor, the community maternal health services in Sudan are well structured with formally trained VMWs, regularly reporting back to a regional RHV, in a stable environment. Many of these VMWs had participated in previous community research studies and were likely, therefore, to be motivated towards improving their clinical practices. Another potential limitation was the pre-post study design and duration which were chosen for pragmatic reasons, including limited funding. With this study design, we cannot be certain that the observed improvements in the perinatal outcomes were due to HBBT $^{+\mathrm{RPPSP}}$ alone. However, we are confident that no other changes in midwifery practice and/or new health/educational initiatives were introduced during the study period. In addition, because of the frequent personal interactions between the VMWs and the field researchers, we believe the reported FSB and ENND rates are reliable. We did not have the causes of neonatal deaths in this home-birth study, as establishing valid and reliable causes of perinatal deaths even in birthing facilities of resource-limited countries is challenging. ${ }^{26}$ However, a previous study of 13000 deliveries in this area (East Nile, Khartoum State) showed that asphyxia contributed to half of all the first-week ENND. ${ }^{3}$

In conclusion, training VMWs in $\mathrm{HBBT}^{+\mathrm{RPPSP}}$ was associated with positive changes in newborn resuscitation practices and improvements in FSB and ENND rates that could reap immense benefits if propagated nationally to all 17000 VMWs in Sudan.

Acknowledgements We would like to thank the research field officers and the VMWs from the East Nile locality for their generosity in participating in this study, and also Professor George Little, Dr Carol Little, Ms Vicki Flanagan (AAP), Ms Lisa Clarke and Ms Meghan Clarke for travelling to Sudan for the inaugural HBB provider and instructor training courses. Without them, this study would not have been possible.

Funding This study was funded by the Irish Aid Civil Society Grant scheme.

Competing interests None declared.

Provenance and peer review Not commissioned; externally peer reviewed.

Data sharing statement All available data can be obtained by contacting the corresponding author.

(C) Article author(s) (or their employer(s) unless otherwise stated in the text of the article) 2017. All rights reserved. No commercial use is permitted unless otherwise expressly granted.

\section{REFERENCES}

1 Sudan Household Health Survey Second Round. Federal Ministry of Health, Ministry of Health, Government of Sudan, Central Bureau of Statistics, Southern Sudan Commission of Census, Statistics \& Evaluation. 2006.

2 Sudan Household Health Survey First Round. Federal Ministry of Health, Ministry of Health, Government of Sudan, Central Bureau of Statistics, Southern Sudan Commission of Census, Statistics \& Evaluation. 2010.

3 Ibrahim SA. Cohort study of perinatal and early neonatal mortality in a rural community in Sudan. MD Thesis. Sudan: University of Khartoum 1994.

4 Annual Statistical Reports. National Information Centre, Ministry of Health, Republic of Sudan. 74, 2010

5 American Academy of Pediatrics. Helping Babies Breathe 2010. https://www.aap.org/ en-us/continuing-medical-education/life-support/Pages/Life-Support.aspx (accessed 26 May 2017).

6 Singhal N, Lockyer J, Fidler H, et al. Helping babies Breathe: global neonatal resuscitation program development and formative educational evaluation. Resuscitation 2012;83:90-6.

7 Lee ACC, Cousens S, Wall SN, et al. Neonatal resuscitation and immediate newborn assessment and stimulation for the prevention of neonatal deaths: a systematic 
review, meta-analysis and Delphi estimation of mortality effect. BMC Public Health 2011;11(Suppl 3):S12.

8 Msemo G, Massawe A, Mmbando D, et al. Newborn mortality and fresh stillbirth rates in Tanzania after helping babies breathe training. Pediatrics 2013;131:e353-60.

9 Goudar SS, Dhaded SM, McClure EM, et al. ENC training reduces perinatal mortality in Karnataka, India. J Matern Fetal Neonatal Med 2012;25:568-74.

10 Goudar SS, Somannavar MS, Clark R, et al. Stillbirth and Newborn Mortality in India after helping babies breathe training. Pediatrics 2013;131:e344-52.

11 Kc A, Wrammert J, Nelin V, et al. Evaluation of helping babies breathe Quality Improvement Cycle (HBB-QIC) on retention of neonatal resuscitation skills six months after training in Nepal. BMC Pediatr 2017;17:103.

12 Mduma E, Ersdal H, Svensen E, et al. Frequent brief on-site simulation training and reduction in 24-h neonatal mortality - An educational intervention study. Resuscitation 2015;93:1-7.

13 Carlo WA, Goudar SS, Jehan I, et al. Newborn-Care Training and Perinatal Mortality in developing countries. N Eng/ J Med Overseas Ed 2010;362:614-23.

14 Bang A, Patel A, Bellad R, et al. Helping babies Breathe (HBB) training: what happens to knowledge and skills over time? BMC Pregnancy Childbirth 2016;22:364.

15 Dempsey E, Pammi M, Ryan AC, et al. Standardised formal resuscitation training programmes for reducing mortality and morbidity in newborn infants. Cochrane Database Syst Rev 2015;9:CD009106.
16 ME Arabi A, Ibrahim SA, Ahmed SE, et al. Skills retention in sudanese village midwives 1-year following Helping babies breathe training. Arch Dis Child 2016;101:439-42.

17 Ibrahim SA, Omer MIA, Amin IK, et al. The role of the village midwife in detection of high risk pregnancies and newborns. Int J Gynaecol Obstet 1992;39:117-22.

18 Laerdal. NeoNatalie: realistic and affordable training and therapy. www.laerdal.info/ neonatalie (accessed 26 May 2017).

19 Niermeyer S, Keenan WJ, Little GA, et al. eds. Helping babies Breathe, Learner Workbook. Elk Grove, IL: American Academy of Pediatrics, 2010.

20 StataCorp. Stata Statistical Software: release 14. College Station, TX: StataCorp, 2015

21 Lunze K, Bloom DE, Jamison DT, et al. The global burden of neonatal hypothermia: systematic review of a Major challenge for newborn survival. BMC Med 2013;11:24.

22 Onalo R. Neonatal hypothermia in sub-Saharan Africa: a review. Niger I Clin Pract 2013;16:129-38.

23 Carrasco M, Martell M, Estol PC, et al. Oronasopharyngeal suction at birth: effects on arterial oxygen saturation. J Pediatr 1997;130:832-4.

24 Bang AT, Bang RA, Baitule SB, et al. Management of birth asphyxia in home deliveries in rural gadchiroli: the effect of two types of birth attendants and of resuscitating with Mouth-to-Mouth, Tube-Mask or Bag-Mask. J Perinatol 2005;25(Suppl 1):S82-91.

25 Reisman J, Arlington L, Jensen L, et al. Newborn resuscitation training in ResourceLimited Settings: a Systematic Literature Review. Pediatrics 2016;138:e20154490.

26 Elamin S, Langhoff-Roos J, Boedker B, et al. Classification of perinatal death in a developing country. Int I Gynaecol Obstr 2003;80:327-33. 


\section{ADC Perinatal outcomes following Helping Babies Breathe training and regular peer -peer skills practice among village midwives in Sudan}

AME Arabi, SA Ibrahim, M Abdel-Rahman, MS Abdalla, SE Ahmed, EP

Dempsey and CA Ryan

Arch Dis Child published online August 18, 2017

Updated information and services can be found at:

http://adc.bmj.com/content/early/2017/08/18/archdischild-2017-31280 9

These include:

References This article cites 18 articles, 4 of which you can access for free at: http://adc.bmj.com/content/early/2017/08/18/archdischild-2017-31280 9\#BIBL

Email alerting

Receive free email alerts when new articles cite this article. Sign up in the service box at the top right corner of the online article.

\section{Notes}

To request permissions go to:

http://group.bmj.com/group/rights-licensing/permissions

To order reprints go to:

http://journals.bmj.com/cgi/reprintform

To subscribe to BMJ go to:

http://group.bmj.com/subscribe/ 